See Article page 1820.

\section{Commentary: Striking the right chord}

\author{
Lawrence M. Wei, MD, and Vinay Badhwar, MD
}

In this issue of the Journal, Budra and colleagues ${ }^{1}$ report the first mid-term results of transventricular mitral valve (MV) repair with the NeoChord DS1000 Artificial Chordae Delivery System (NeoChord, St Louis Park, Minn). This device aims to treat primary mitral regurgitation (MR) by implantation of expanded polytetrafluoroethylene (ePTFE) sutures to prolapsing or flail MV leaflet segments via a transapical approach on the beating heart. The highly experienced surgeon coauthors with access to the NeoChord device before current clinical trials were among the first to perform these operations. They are to be highly commended for their diligent and honest efforts to explore this novel technology.

The preferred therapy for severe primary degenerative MR is MV repair, receiving class 1 guideline recommendation. ${ }^{2}$ Surgical MV repair technique has evolved to include a multitude of options, including implantation of artificial chordae, all with highly reproducible outcomes and durability, with repair rates $>95 \%$ for focal disease in experienced centers. ${ }^{3-6}$ Multiple centers regularly use minimally invasive approaches, including robotic assistance, to achieve excellent short-term outcome, $>95 \%$ repair, and 1-year durability with less than mild MR while eliminating the morbidity of sternotomy. ${ }^{4,5}$ Long-term freedom from recurrent moderate or severe MR following MV repair has been reported as high as $87.5 \%$ at 20 years. ${ }^{6}$ Newer technologies, such as the NeoChord device, laudably seek to achieve similar outcomes without the use of cardiopulmonary bypass. Implantation of chordae with the NeoChord device has achieved proof-of-concept as feasible, with

\footnotetext{
From the Department of Cardiovascular and Thoracic Surgery, West Virginia University, Morgantown, WVa.

Disclosures: The authors reported no conflicts of interest.

The Journal policy requires editors and reviewers to disclose conflicts of interest and to decline handling or reviewing manuscripts for which they may have a conflict of interest. The editors and reviewers of this article have no conflicts of interest.

Received for publication Dec 30, 2020; revisions received Dec 30, 2020; accepted for publication Jan 4, 2021; available ahead of print Jan 10, 2021.

Address for reprints: Vinay Badhwar, MD, Department of Cardiovascular and Thoracic Surgery, West Virginia University, 1 Medical Center Dr, PO Box 8059, Morgantown, WV 26506 (E-mail: vinay.badhwar@wvumedicine.org).

J Thorac Cardiovasc Surg 2022;164:1831-2

$0022-5223 / \$ 36.00$

Copyright (c) 2021 by The American Association for Thoracic Surgery

https://doi.org/10.1016/j.jtcvs.2021.01.002
}

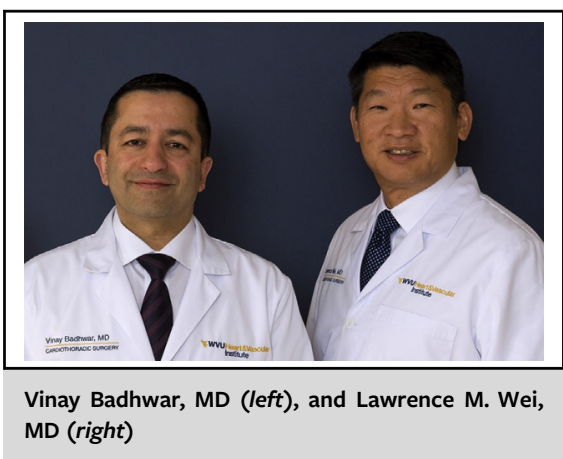

CENTRAL MESSAGE

Mitral therapy with the NeoChord device has a high rate of failure at mid-term follow-up, even in experienced hands.

composite short-term survival and freedom of MR of $84 \%$, but longer-term outcomes are not yet available. ${ }^{7,8}$

Budra and colleagues provide longitudinal outcomes on 88 consecutive patients who underwent transventricular MV repair with the NeoChord device between 2011 and 2017 with a median follow-up of 42 months. Only 59 patients $(67 \%)$ were free of recurrent $\mathrm{MR}>2+$, and even the patients with the simplest pathology (isolated P2 prolapse) had freedom from MR $>2+$ of only $82 \%$. These results did not improve with increasing experience of the surgical team. The authors describe several mechanisms of failure, including rupture of native or artificial chordae, neochordal elongation or dehiscence, and combinations of these mechanisms. Mitral pathology (rather than focal disease) and a dilated left ventricle were 2 factors that significantly increased the risk of MR progression. It might be hypothesized that following NeoChord implantation in the absence of annuloplasty, initial partial relief of MR resulted in remodeling of dilated ventricles and the chordae became elongated, resulting in recurrent MR.

This important experience demonstrates that MV therapy performed with the NeoChord device has an unacceptably high failure rate compared with conventional minimally invasive techniques. The authors are to be congratulated for their transparency and honesty in reporting these results despite being at the forefront of this technology and investing great time and effort in its development. While the outcome of a US randomized clinical trial is still pending, when faced with choices on the treatment of primary MR, 
it appears that even in experienced hands that performance of this technology fails to strike the right chord.

\section{References}

1. Budra M, Januskauskas V, Drasutiene A, Zorinas A, Zakarkaite D, Lipnevieius A et al. Midterm results of transventricular mitral valve repair: single-center experience. J Thorac Cardiovasc Surg. 2022;164:1820-8.

2. Otto CM, Nishimura RA, Bonow RO, Carabello BA, Erwin JP III, Gentile F, et al. 2020 ACC/AHA guideline for the management of patients with valvular heart disease: a report of the American College of Cardiology/American Heart Association Joint Committee on clinical practice guidelines. J Am Coll Cardiol. 2021;77: 450-500.

3. Goldstone AB, Cohen JE, Howard JL, Edwards BB, Acker AL, Hiesinger W, et al. A "repair-all" strategy for degenerative mitral valve disease safely minimizes unnecessary replacement. Ann Thorac Surg. 2015;99:1983-90.
4. Suri RM, Dearani JA, Mihaljevic T, Chitwood WR Jr, Murphy DA, Trento A, et al. Mitral valve repair using robotic technology: safe, effective, and durable. J Thorac Cardiovasc Surg. 2016;151:1450-4.

5. Coyan G, Wei LM, Althouse A, Roberts HG, Schauble D, Murashita T, et al. Robotic mitral valve operations by experienced surgeons are cost-neutral and durable at 1 year. J Thorac Cardiovasc Surg. 2018;156:1040-7.

6. David TE, David CM, Tsang W, Lafreniere-Roula M, Manlhiot C. Long-term results of mitral valve repair for regurgitation due to leaflet prolapse. J Am Coll Cardiol. 2019;74:1044-53.

7. Seeburger J, Rinaldi M, Nielsen SL, Salizzoni S, Lange R, Schoenburg M, et al. Off-pump transapical implantation of artificial neo-chordae to correct mitral regurgitation: the TACT trial (Transapical Artificial Chordae Tendinae) proof of concept. J Am Coll Cardiol. 2014;63:914-9.

8. Rucinskas K, Janusauskas V, Zakarkaite D, Aidietiene S, Samalavicius R, Speziali G, et al. Off-pump transapical implantation of artificial chordae to correct mitral regurgitation: early results of a single-center experience. J Thorac Cardiovasc Surg. 2014;147:95-9. 